\title{
Milling of Technical Ceramics ROCAR SiSiC
}

Dana Stancekova ${ }^{1}$, Jozef Mrázik ${ }^{1}$, Ingrid Görögová2 ${ }^{2}$ Izabela Miturska ${ }^{3}$, Peter Ščotka ${ }^{4}$, Filip Turian ${ }^{1}$

${ }^{1}$ University of Zilina, Faculty of Mechanical Engineering, Zilina, Slovak Republic, dana.stancekova@fstroj.uniza.sk,jozef.mrazik@fstroj.uniza.sk,

2Institute of Production Technologies, Slovak University of Technology in Bratislava, Slovakia, qgorogova@stuba.sk

3Lublin University of Technology, Faculty of Mechanical Engineering, Lublin, Poland, i.mturska@pollub.pl

4VIKO s.r.o, Považská Teplá 529, Slovak Republic, pscotka@scotka.sk

The paper deals with hard machining of ceramic construction materials that are still more applied in the automobile industry as well as other branches due to their specific properties, such as hardness, corrosion resistance, heat resistance, etc. Concretely, we speak of milling of technical ceramics ROCAR SiSiC. Our intention is the right selection of suitable tool materials, tool geometry as well as a definition of optimum cutting parameters by the minimum cost. After the selection of optimum technology, identified cutting plates were compared and experimentally verified in the process. Results of verifications the right choice of selected cutting plate is a comparison of components of cutting force originating in the process of machining and also the quality of machined surfaces after milling of hard and brittle material.

Keywords: milling, technical ceramics, cutting forces, surface quality

\section{Introduction}

Science and technology are in permanent development. That leads towards still more demanding and intelligent technologies. Material requirements increase at the same speed. An achievement of lighter elements to save energy together with a quality increase for higher security and durability also belong to these requirements. In summary, the cost-effectiveness plays a key role. Ceramic materials have significantly contributed to innovation processes. [1-3]

Ceramics can be applied in fields where metal materials work on their limits in performance. Properties of a system that is under pressure in heat, tribology or abrasion improve due to technical ceramics or, moreover, they cannot be realized without technical ceramics. For designers, technical ceramics provides an opportunity for modern examples based on their improved mechanical properties. [4,5]

\section{Machining of ceramics ROCAR SiSiC by Milling}

Regarding the fact that technical ceramic material is similar to glass by its hardness and it is very brittle, its machining by conventional technologies is rather demanding. Below-stated experimental verifications deal with an investigation of a possibility of milling of such material with an impact on the machining process and final effects. [6-9]

A CNC machining centre HURCO VMX 30t was applied for milling $[10,11]$. It is a three-axial vertical machining centre with the CNC control centre Ulti$\max$ (Fig.1)

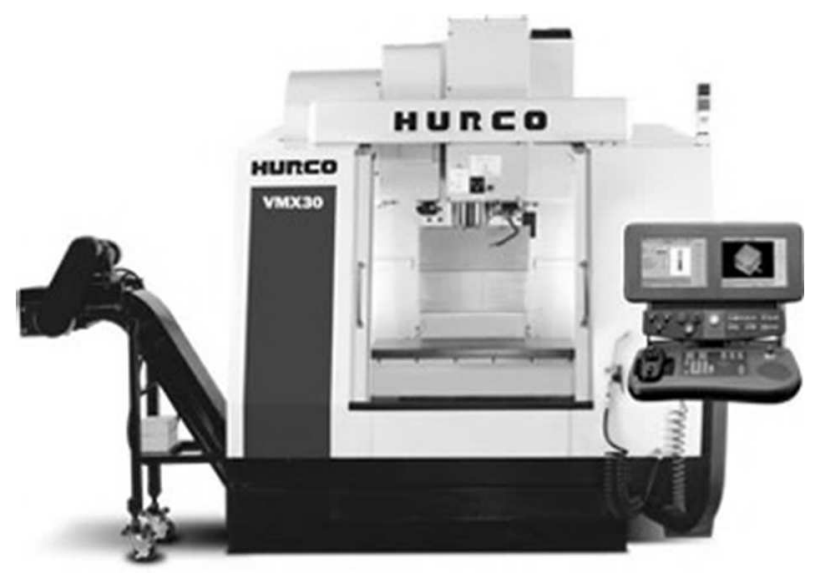

Fig. 1CNC machining centre HURCO VMX $30 t$

2.1 The applied tool

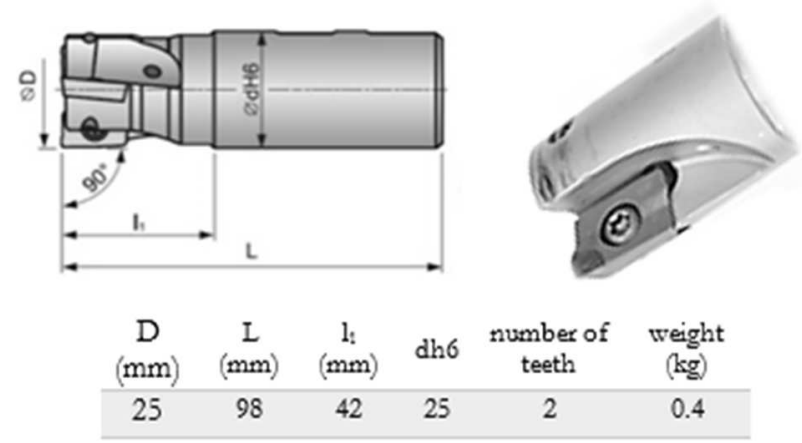

Fig. 2 The parameters of the end mill 25A2R042B25SAP16D-C 
As a specified tool for face milling, the end mill 25A2R042B25-SAP16D-C was selected. Two indexable cutting inserts can be attached to it with the angle of setting of the cutting insert of $90^{\circ}$. (Fig. 2)

Experimental verifications of milling of the selected material were defined 3 different PCD cutting inserts.

\section{a) The cutting insert ADKW 150502x45 PDR ID5 (Fig.3)}

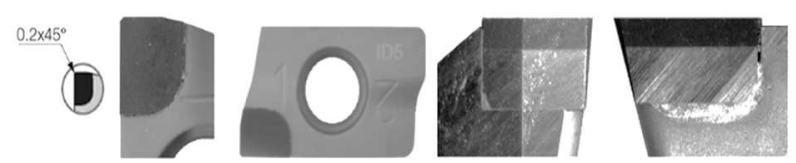

Fig. 3 The cutting insert ADKW 150502X45 PDR ID5

b) The cutting insert ADKW 150508 PDR ID5 (Fig.4)

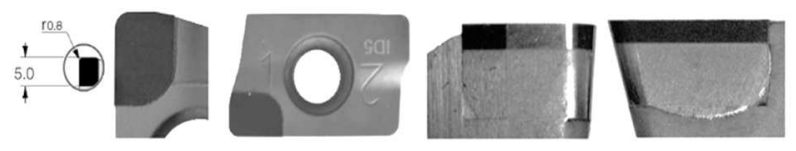

Fig. 4 The cutting insert ADKW 150508 PDR ID5

c) The cutting insert ADKW 150508 PDR ID8 (Fig.5)
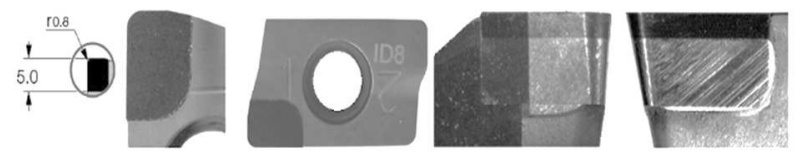

Fig. 5 The cutting insert ADKW 150508 PDR ID8

\subsection{Machined material}

Tab. 1 Physical and mechanical properties of SiSiC

Physical properties

\begin{tabular}{lr}
\hline Density $\left(\mathrm{g} \cdot \mathrm{cm}^{-3}\right)$ & 3.07 \\
\hline Water absorption $(\%)$ & 0 \\
\hline Porosity $(\%)$ & 0 \\
\hline Permeability & 0 \\
\hline Weibull modulus & $>14$ \\
\hline Mechanical properties & 1200 \\
\hline & $(\mathrm{Si}) / 2700$ \\
Hardness (HV) & $(\mathrm{SiC})$ \\
& 350 \\
\hline Tensile strength $(\mathrm{MPa})$ & 395 \\
\hline Tensile load modulus $(\mathrm{GPa})$ & 350 \\
\hline Bending strength at $20^{\circ} \mathrm{C}(\mathrm{MPa})$ & 3500 \\
\hline Compressive strength $(\mathrm{MPa})$ & 0.17 \\
\hline Poisson number & 4.0 \\
\hline Fracture toughness $\left(\mathrm{MPa} \cdot \mathrm{m}^{1 / 2}\right)$ & 169 \\
\hline Modulus of elasticity in shear & \\
(GPa) &
\end{tabular}

The ceramic material ROCAR SiG SiSiC with the fine-grained structure (Fig. 6, Tab.1, 2) was machined. It was by the company CeramTec, dimensions of the workpiece 210 x 110 x 10 (mm)
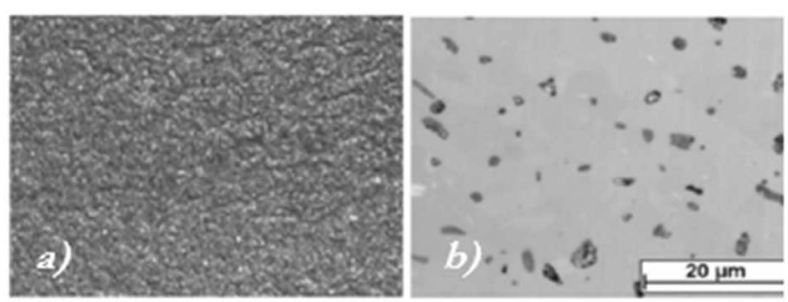

Fig. 6 The ceramic surface SiSiC a) The surface SiSiC seen with the unaided eye b) The microstructure of the surface Si$\mathrm{SiC}$

\subsection{Cutting conditions}

Cutting conditions were defined regarding the milling insert from PCD and the machined material SiSiC. We followed recommendations for cutting conditions [12-14]. The milling cutting conditions:

- cutting speed $\mathrm{v}_{\mathrm{c}}=70 \mathrm{~m} \cdot \mathrm{min}^{-1}$

- feed pre tooth $\mathrm{f}_{\mathrm{z}}=0.015 \mathrm{~mm}$

- $\operatorname{revs} \mathrm{n}=891 \mathrm{~min}^{-1}$

- cutting depth $a_{p}=0.07 ; 0.01 ; 0.12 ; 0.15 ; 0.16$ $\mathrm{mm}$

\section{Experimental verifications}

Previous experiments confirmed that adverse effects and edge cleavage in an instrument contact take place due to brittleness of ceramics and tool sharpness. It is necessary to grind a leading edge of a workpiece to avoid the damage of a machined sample. We formed the leading edge at the angle of $2^{\circ}$ on the machined sample. Grinding was performed on the grinding machine $\mathrm{BH}-20$ by means of a diamond grinding wheel, Fig. 7.

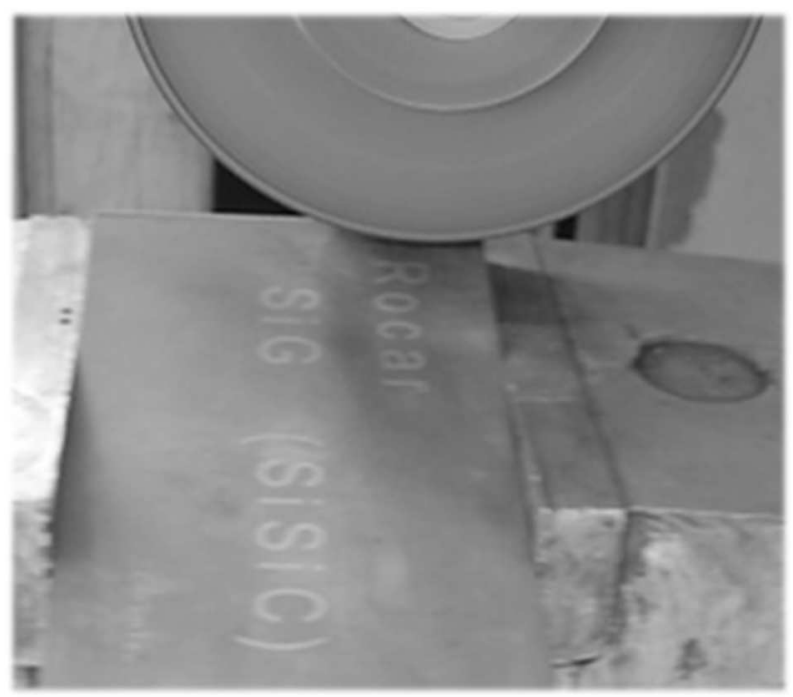

Fig. 7 Cutting of an edge by the diamond wheel 


\subsection{Evaluation of cutting force}

During machining, we measured folders of the cutting force $F_{c}, F_{p}$ and $F_{f}$ on the 3-component piezoelectric dynamometer KISTLER 9255 A, Fig.8. Measurements were performed for each insert separately as well as the individual cutting conditions (Tab. 2 - 4., Fig. 9 -12)

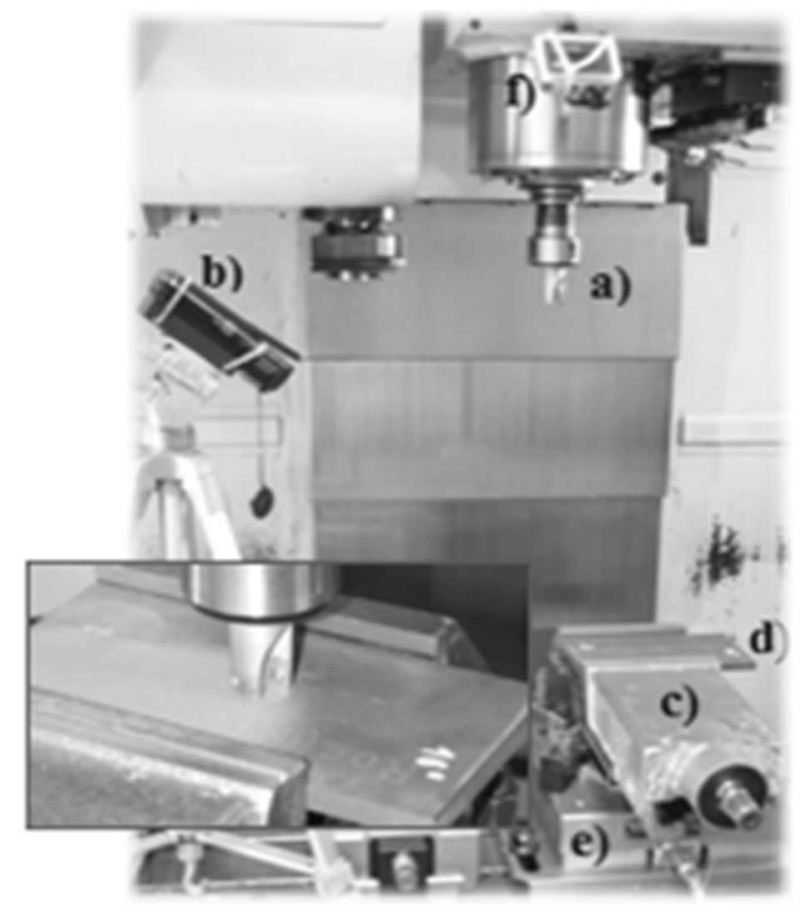

Fig. 8 Experiment procedure a) the milling machine b) the infrared camera MobIR M8, c) the vice d) the machined sample e) dynamometer KISTLER 9255 A, f) the camera GoPro

\section{a) The cutting insert ADKW 150502x45 PDR ID5}

Tab. 2 Folders of the cutting force in milling by the tool ADKW 150502×45 PDR ID5

\begin{tabular}{|c|c|c|c|c|c|}
\hline $\mathrm{a}_{\mathrm{p}}(\mathrm{mm})$ & 0.06 & 0.09 & 0.12 & 0.15 & 0.16 \\
\hline $\mathrm{F}_{\mathrm{c}}(\mathrm{N})$ & 2.34 & 9.38 & 26.56 & 42.97 & 99.22 \\
\hline $\mathrm{F}_{\mathrm{p}}(\mathrm{N})$ & 2.44 & 36.13 & 42.97 & 80.57 & 85.94 \\
\hline $\mathrm{F}_{\mathrm{f}}(\mathrm{N})$ & 2.56 & 18.8 & 21.08 & 63.23 & 75.2 \\
\hline $\mathrm{F}(\mathrm{N})$ & 4.24 & 41.79 & 54.73 & 111.06 & 151.28 \\
\hline
\end{tabular}

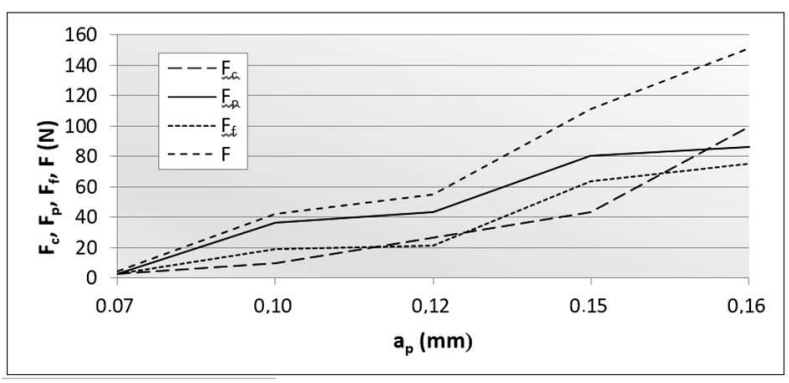

Fig. 9 The impact of $a_{p}$ on the size of folders of cutting forces, $v_{c}=70 \mathrm{~m} \cdot \mathrm{min}^{-1}, f_{z}=0.015 \mathrm{~mm}$

b) The cutting insert ADKW 150508 PDR ID5

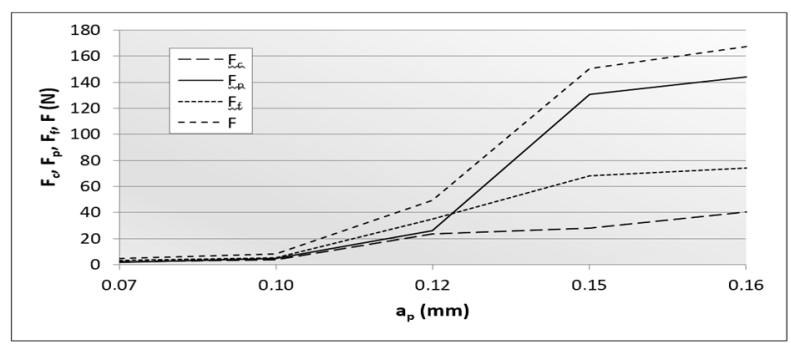

Fig. 10 The impact of ap on the size of folders of cutting forces, $v c=70 \mathrm{~m} . \mathrm{min}-1, f_{z}=0.015 \mathrm{~mm}$

Tab. 3 Folders of the cutting force in milling by the tool ADKW 150508 PDR ID5

\begin{tabular}{|c|c|c|c|c|c|}
\hline$a_{p}(\mathrm{~mm})$ & 0.06 & 0.09 & 0.12 & 0.15 & 0.16 \\
\hline$F_{c}(\mathrm{~N})$ & 2.34 & 3.91 & 23.44 & 28.31 & 40.63 \\
\hline$F_{p}(\mathrm{~N})$ & 1.91 & 4.88 & 25.88 & 130.86 & 144,04 \\
\hline$F_{f}(\mathrm{~N})$ & 3.42 & 5.13 & 35.03 & 68.36 & 74.34 \\
\hline$F(\mathrm{~N})$ & 4.56 & 8.09 & 49.46 & 150.33 & 167.10 \\
\hline
\end{tabular}

\section{c) The cutting insert ADKW 150508 PDR IDS}

Tab. 4 Folders of the cutting force in milling by the tool ADKW 150508 PDR ID8

\begin{tabular}{|c|c|c|c|c|c|}
\hline$a_{p}(\mathrm{~mm})$ & 0.06 & 0.09 & 0.12 & 0.15 & 0.16 \\
\hline$F_{c}(\mathrm{~N})$ & 3.13 & 10.16 & 25.78 & 37.5 & 130.47 \\
\hline$F_{p}(\mathrm{~N})$ & 0.49 & 16.6 & 70.88 & 91.8 & 137.85 \\
\hline$F_{f}(\mathrm{~N})$ & 5.13 & 12.82 & 35.89 & 56.4 & 125.61 \\
\hline$F(\mathrm{~N})$ & 6.03 & 23.31 & 83.53 & 114.08 & 227.60 \\
\hline
\end{tabular}




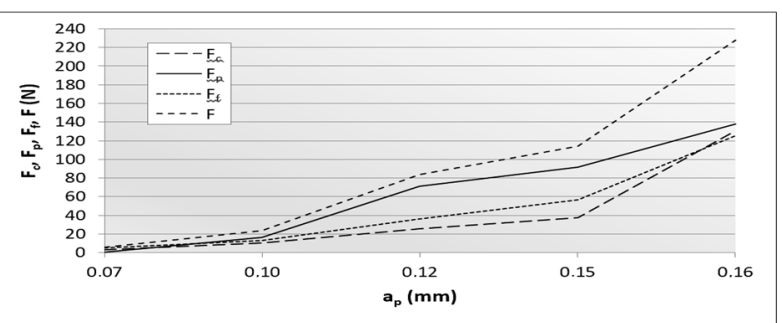

Fig. 11 The impact of $a_{p}$ on the size of folders of cutting forces, $v_{c}=70 \mathrm{~m} . \mathrm{min}^{-1}, f_{\mathrm{z}}=0.015 \mathrm{~mm}$

Evaluation of the resulting force $F$

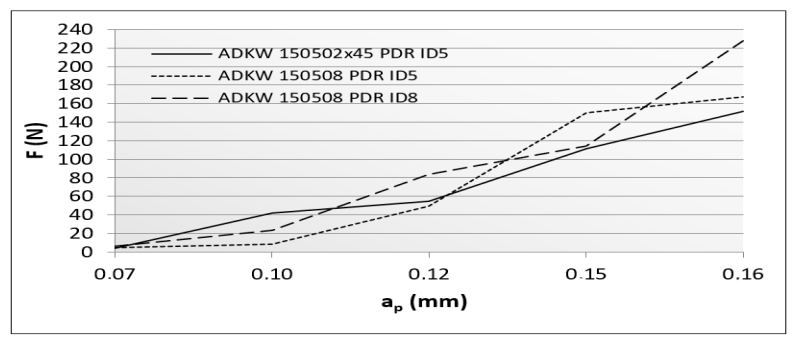

Fig. 12 Effect of $a_{p}$ on the resultant cutting force $F, v_{c}=70$ m.min ${ }^{-1}, f_{z}=0.015 \mathrm{~mm}$

In Figure 12, one may observe that in given cutting conditions, the resulting force $\mathrm{F}$ increases with an increased cutting depth $a_{p}$. The highest cutting forces and thus the resulting force $F=227.603 \mathrm{~N}$ was measured by the milling with the milling tool ADKW 150508 PDR ID8 with the radius of the rounding of the cutting edge $r_{n}=0.8 \mathrm{~mm}$. With the milling tool ADKW 150508 PDR ID5 we measured the resulting force $F=167.107 \mathrm{~N}$ with $r_{n}=0.8 \mathrm{~mm}$. The lowest resulting force $F=151.271 \mathrm{~N}$ was measured in the milling tool ADKW 150502x45 PDR ID5 with the bezel $0.2 \times 45^{\circ}$.

\section{Summary of cutting forces}

The result of measured cutting forces is that components of the cutting force $F_{c}, F_{p}, F_{f}$ increase with an increase of cutting depths and thus also the resulting force $F$. The lowest resulting force $F=151.271 \mathrm{~N}$ was measured in the milling tool ADKW 150502x45 PDR ID5 with the bezel $0.2 \times 45^{\circ}$. On the contrary, the highest cutting forces and thus the resulting force $F=$ 227.603 $\mathrm{N}$ was measured by the milling with the milling tool ADKW 150508 PDR ID8 with the radius of the rounding of the cutting edge $r_{n}=0.8 \mathrm{~mm}$. With the milling tool ADKW 150508 PDR ID5 we measured the resulting force $F=167.107 \mathrm{~N}$ with $r_{n}=0.8$ $\mathrm{mm}$. From the comparison of milling tools, we may assume that by milling by the inserts with the rounded cutting edge, we measured higher cutting forces. High cutting forces mean high performance, they lead to system instability which causes vibrations and they cause higher deformation of cutting tools and workpieces. Cutting forces are affected especially by workpiece materials (the harder is the workpiece material, the higher cutting forces take place), tool geometry and applied cutting conditions.

\subsection{Surface quality after machining}

Generally, an important parameter of a produced component is its quality. Therefore, we evaluated important indicators of surface roughness. For each cutting depth the functional parameters of proportion were measured: Rk, Rpk, Rvk, Mr1, Mr2, (Tab. 5-7, Fig. 13-18).

\section{Functional parameters of the machined surface}

\section{a) The cutting insert ADKW 150502x45 PDR ID5}

Tab. 5 The functional parameters of the machined area by the milling insert ADKW 150502×45 PDR ID5

\begin{tabular}{llllll}
\hline $\mathbf{a}_{\mathbf{p}}(\mathbf{m m})$ & $\mathbf{0 . 0 6}$ & $\mathbf{0 . 0 9}$ & $\mathbf{0 . 1 2}$ & $\mathbf{0 . 1 5}$ & $\mathbf{0 . 1 6}$ \\
\hline Rpk $(\mu \mathrm{m})$ & 0.36 & 0.25 & 0.35 & 0.33 & 0.29 \\
\hline $\operatorname{Rk}(\mu \mathrm{m})$ & 0.81 & 0.77 & 0.85 & 0.73 & 0.86 \\
\hline $\operatorname{Rvk}(\mu \mathrm{m})$ & 1.35 & 0.82 & 0.87 & 0.9 & 0.72 \\
\hline $\operatorname{Mr} 1 \%)$ & 7.59 & 5.17 & 6.93 & 6.41 & 7.46 \\
\hline $\operatorname{Mr} 2(\%)$ & 84.4 & 83.7 & 78.6 & 81.1 & 82.6
\end{tabular}

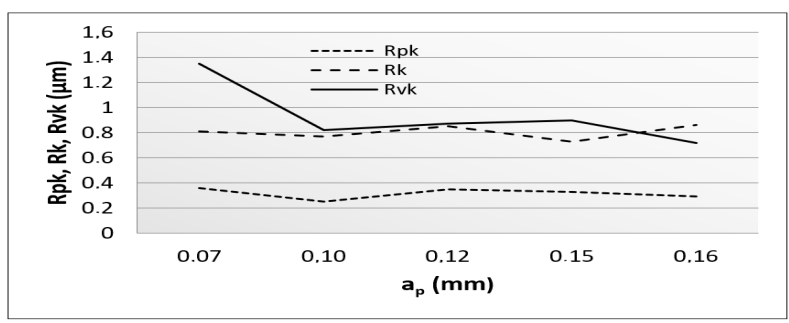

Fig. 13 The impact of $a_{p}$ on functional parameters of the sur-

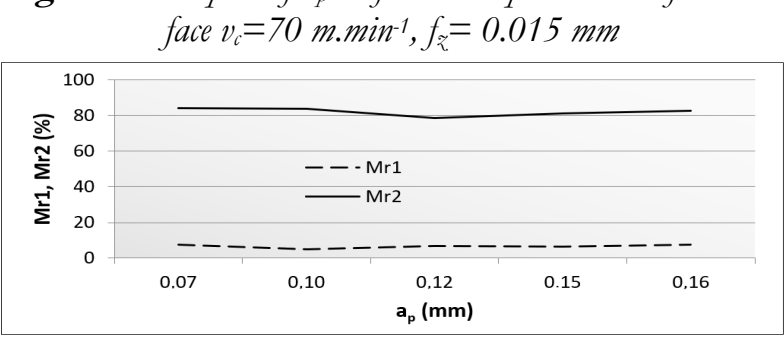

Fig. 14 The impact of $a_{p}$ on the material proportion

b) The cutting insert ADKW 150508 PDR ID5

Tab. 6 The functional parameters of the machined area by the milling insert ADKW 150508 PDR ID5

\begin{tabular}{llllll}
\hline $\boldsymbol{a}_{\boldsymbol{p}}(\mathbf{m m})$ & $\mathbf{0 . 0 6}$ & $\mathbf{0 . 0 9}$ & $\mathbf{0 . 1 2}$ & $\mathbf{0 . 1 5}$ & $\mathbf{0 . 1 6}$ \\
\hline$R \not k(\mu \mathrm{m})$ & 0.16 & 0.33 & 0.27 & 0.23 & 0.21 \\
\hline$R k(\mu \mathrm{m})$ & 0.49 & 0.61 & 0.7 & 0.6 & 0.84 \\
$R v k(\mu \mathrm{m})$ & 0.49 & 0.41 & 0.57 & 0.49 & 1.07 \\
\hline$M r 1(\%)$ & 8.7 & 7.33 & 6.94 & 6.73 & 6.18 \\
\hline$M r 2(\%)$ & 81.1 & 83.0 & 80.1 & 80.2 & 82.0
\end{tabular}




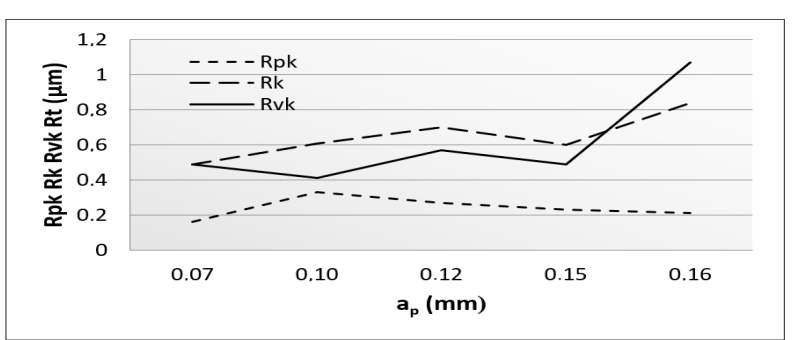

Fig. 15 The impact of ap on functional parameters of the surface, $v c=70 \mathrm{~m} . \mathrm{min}-1, f_{z}=0.015 \mathrm{~mm}$

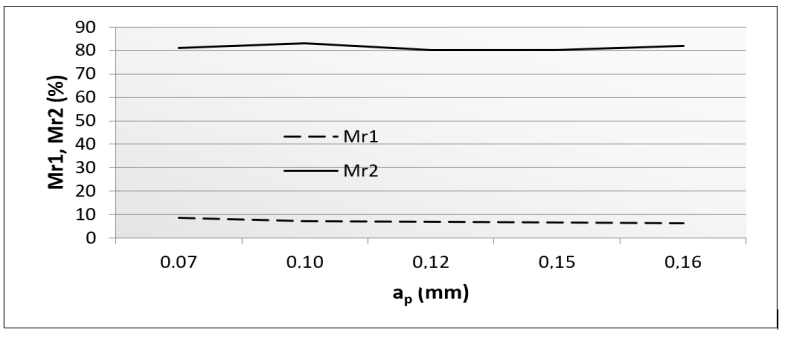

Fig. 16 The impact of ap on the material proportion

c) The cutting insert ADKW 150508 PDR IDs

Tab. 7 The functional parameters of the machined area by the milling insert ADKW 150508 PDR ID8

\begin{tabular}{llllll}
\hline $\boldsymbol{a}_{\boldsymbol{p}}(\mathbf{m m})$ & $\mathbf{0 . 0 6}$ & $\mathbf{0 . 0 9}$ & $\mathbf{0 . 1 2}$ & $\mathbf{0 . 1 5}$ & $\mathbf{0 . 1 6}$ \\
\hline$R \not k(\mu \mathrm{m})$ & 0.22 & 0.5 & 0.42 & 0.14 & 0.17 \\
\hline$R k(\mu \mathrm{m})$ & 0.7 & 0.81 & 0.97 & 0.76 & 0.94 \\
\hline$R v k(\mu \mathrm{m})$ & 0.63 & 1.11 & 1.01 & 0.62 & 0.58 \\
\hline$M r 1(\%)$ & 7.79 & 6.51 & 5.17 & 5.63 & 8.09 \\
$M r 2(\%)$ & 84.7 & 81.2 & 84.2 & 86.6 & 85.1 \\
\hline
\end{tabular}

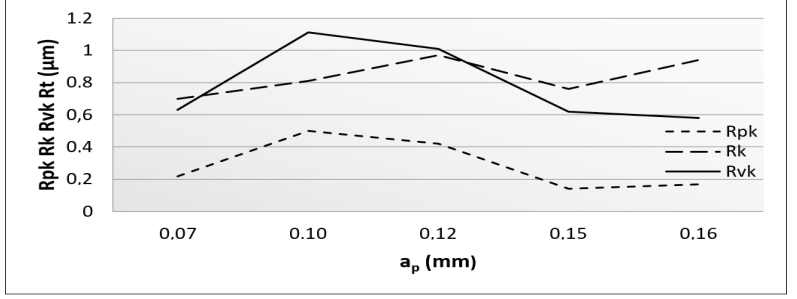

Fig. 17 The impact of ap on functional parameters of the surface, $v c=70 \mathrm{~m} . \mathrm{min}-1, f_{z}=0.015 \mathrm{~mm}$

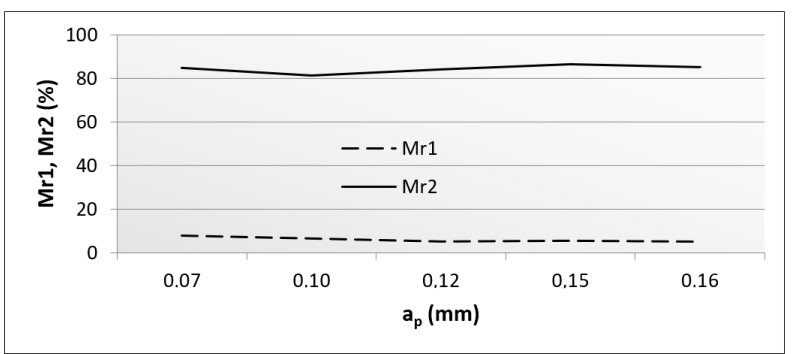

Fig. 18 The impact of ap on the material proportion

The evaluation of functional parameters of the surface

\section{Grain depth of roughness $R k$}

Grain depth of roughness $R k$ is a measurement of nominal roughness (peaks, valleys) and it is an indicator of mechanical resistance against depreciation. It may be applied as a substitution for parameters of roughness $\mathrm{Ra}$, Rt and $\mathrm{Rz}$ in conditions where anomalous peaks and depressions may negatively affect reproducibility of these parameters. Low values $\mathrm{Rk}$ mean a possibility of higher mechanical loading of the material, fig. 19.

The lowest values of $R k$ were measured in the areas by milling by means of the milling insert ADKW 150508 PDR ID5, namely $R k=0.49 \mu \mathrm{m}$ at $a_{p}=0.06$ $\mathrm{mm}$. That means that the surface has hard roughness of grain. On the contrary, the highest value was measured by milling by means of the insert ADKW 150508 PDR ID8 Rk $=0.97 \mu \mathrm{m}$, in the cutting depth $a_{p}=0.12 \mathrm{~mm}$. That means the surface has open roughness of grain.

Based on the measured values (Tab. 8), we may conclude that values $R k$ are low and the surface is capable to resist high mechanical depreciation. In comparison with the unmachined surface $(R k=20.9$ $\mu \mathrm{m})$, the values decreased approximately by $19.93 \mu \mathrm{m}$.

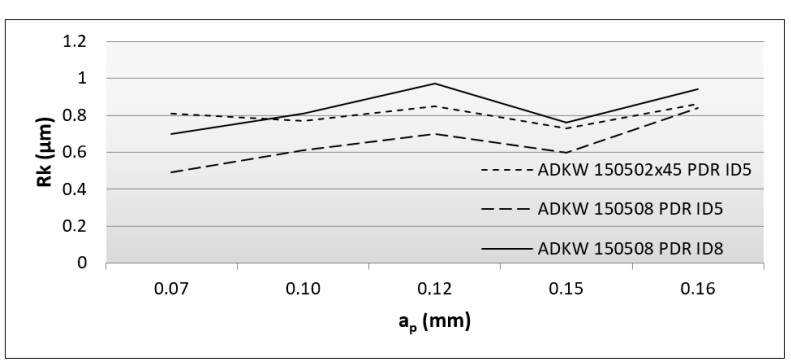

Fig. 19 The impact of $a_{p}$ on grain depth of roughness

Tab. $\boldsymbol{8}$ The lowest value of Rk in the cutting depth $a_{p}$

\begin{tabular}{lcc} 
Order of inserts & $R k(\mu \mathrm{m})$ & $a_{p}(\mathrm{~mm})$ \\
\hline ADKW 150508 PDR ID5 & $\mathbf{0 . 4 9}$ & 0.07 \\
ADKW 150508 PDR ID8 & 0.7 & 0.07 \\
ADKW 150502x45 PDR ID5 & 0.73 & 0.15
\end{tabular}

\section{Reduced peak height Rpk}

High values of a reduced peak height Rpk mean that the surface consists of high peaks that have small contact areas and in contact with another surface there originate high tensions. Therefores it is necessary to lubricate the surface to decrease tension between contact areas. Low values of $R p k$ mean that the surface is 
smooth and, e.g., for bearings, there are short runningin periods for bearings. Rpk also represents a nominal material amount that can be removed during operations.

In our case values Rpk for milling by means of the milling insert ADKW 150502x45 PDR ID5 range between $0.25 \div 0.36 \mu \mathrm{m}$, for the insert ADKW 150508 PDR ID5 Rpk $=0.16 \div 0.33 \mu \mathrm{m}$ and for the insert ADKW 150508 PDR ID8 Rpk $=0.14 \div 0.5 \mu \mathrm{m}$, Fig. 20.

Overall, we may assume that values Rpk are low, the surface is smooth for all cutting depths and in machining by means of all types of inserts, Tab. 9 .

The value of the unmachined surface was $R p k=$ $6.39 \mu \mathrm{m}$. It was reduced after machining by approximately $6.03 \mu \mathrm{m}$.

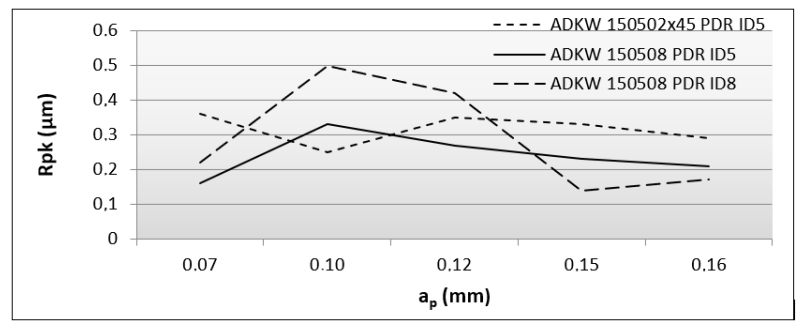

Fig. 20 Effect of ap on reduced peak, height Rpk

Tab. 9 The lowest value of Rpk in the cutting depth $a_{p}$ Order of inserts

\begin{tabular}{|lll|}
\hline ADKW 150508 PDR ID5 & $\mathbf{0 . 1 4}$ & 0.15 \\
\hline ADKW 150508 PDR ID8 & 0.16 & 0.07 \\
\hline ADKW 150502x45 PDR ID5 & 0.25 & 0.10
\end{tabular}

\section{Reduced valley height Rvk}

Reduced valley height $R v k$ is a measurement of valleys under the grain depth of roughness and it relates to the retention of lubricant and chip. The low value of $R v k$ means that the material does not retain lubricants or chip.

In general, we may assume that values of $\mathrm{R} v /$ are low and in valleys, there is captured a minimum of lubricant or chip. Values for the milling insert ADKW 150502x45 PDR ID5 reach Rvk $=0.72 \div 1.35 \mu \mathrm{m}$, for the insert ADKW 150508 PDR ID5 Rvk $=0.41 \div 1.07$ $\mu \mathrm{m}$ and for the insert ADKW 150508 PDR ID8 Rvk $=0.58 \div 1.11 \mu \mathrm{m}$. The unmachined workpiece with the value $R v k=9.59 \mu \mathrm{m}$ had a decrease approximately by $8.792 \mu \mathrm{m}$, Fig. 21, Tab. 10.

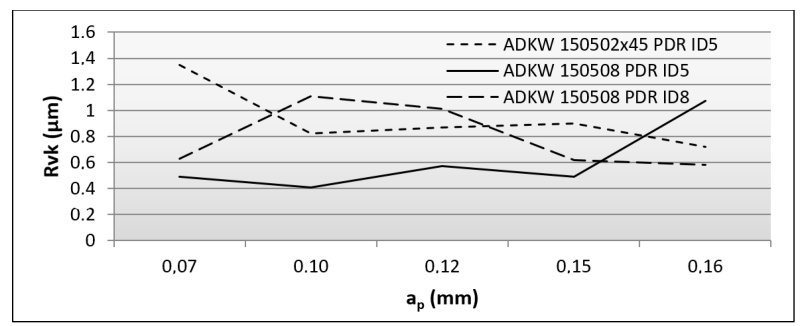

Fig. 21 Effect of ap on reduced groove depth Rvk
Tab. 10 The lowest value of Rvk in the cutting depth $a_{p}$

\begin{tabular}{lcc}
\hline Order of inserts & $R v k(\mu \mathrm{m})$ & $a_{p}(\mathrm{~mm})$ \\
\hline ADKW 150508 PDR ID5 & $\mathbf{0 . 4 1}$ & 0.10 \\
\hline ADKW 150508 PDR ID8 & 0.58 & 0.15 \\
\hline ADKW 150502x45 PDR ID5 & 0.72 & 0.16
\end{tabular}

\section{Material ratio Mr1 (peaks)}

The unmachined surface $M r 1=10.5 \%$, a decrease after machining by approximately $3.858 \%$.

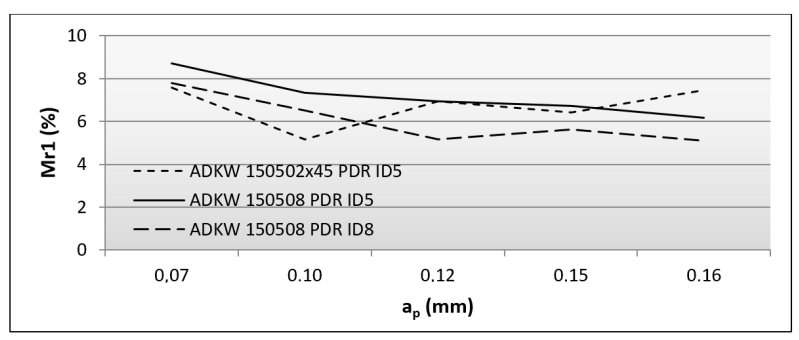

Fig. 22 Influence $a_{p}$ on material ratio $\mathrm{Mr1}$

Tab. 11 The lowest value Mr1 in the cutting depth $a_{p}$

\begin{tabular}{lcc}
\hline Order of inserts & $M r 1(\%)$ & $a_{p}(\mathrm{~mm})$ \\
\hline ADKW 150508 PDR ID5 & 5.09 & 0.16 \\
\hline ADKW 150508 PDR ID8 & 5.17 & 0.09 \\
\hline ADKW 150502x45 PDR ID5 & 6.18 & 0.16
\end{tabular}

\section{Material ratio Mr2 (valleys)}

The unmachined surface $\mathrm{Mr} 2=87.6 \%$, a decrease after machining by approximately $5.03 \%$.

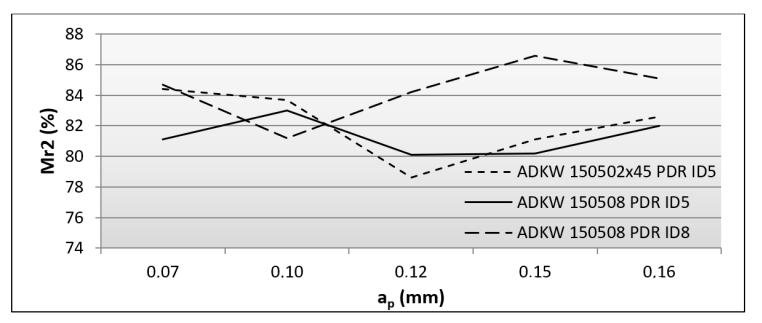

Fig. 23 Influence $a_{p}$ on material ratio $\mathrm{Mr}$

Tab. 12 The lowest value $M r 2$ in the cutting depth $a_{p}$

\begin{tabular}{lcc}
\hline Order of inserts & $M r 2(\%)$ & $a_{p}(\mathrm{~mm})$ \\
\hline ADKW 150508 PDR ID5 & $\mathbf{7 8 . 6}$ & 0.12 \\
\hline ADKW 150508 PDR ID8 & 80.1 & 0.12 \\
\hline ADKW 150502x45 PDR ID5 & 81.2 & 0.09
\end{tabular}

\section{Summary of surface functional parameters}

In the application of three different types of milling inserts and defined cutting depths, the parameter $R k$ varied in the order of small intents. The lowest value Rk was measured in the insert ADKW 150508 PDR ID5 in the cutting depth $a_{p}=0.06 \mathrm{~mm}$ and namely $R k$ $=0.49 \mu \mathrm{m}$.

Values of reduced peak height $R p k$ are low and that means that the surface is smooth with minimum heights of peaks. The lowest value of $R p k$ was measured in the 
insert ADKW 150508 PDR ID8 in the cutting depth $a_{p}=0.15 \mathrm{~mm}$ and the value of Rpk was $0.14 \mu \mathrm{m}$. However, the lowest value of $R v k$ was measured in the insert ADKW 150508 PDR ID5 in the cutting depth $a_{p}=$ $0.09 \mathrm{~mm}$. The value of $R v k$ was $0.41 \mu \mathrm{m}$.

In a comparison of the material ratio of peaks $\mathrm{Mrl}$ and valleys $M r 2$, we found out that the area of valleys prevails over peaks in the ratio $82,57 \%: 6,642 \%$.

\section{Conclusion}

From the comparison of milling inserts, we may assume that in milling by means of the milling inserts with the rounded cutting edge, we measured higher cutting forces. High cutting forces mean high performance, they lead to system instability which causes vibrations and they cause higher deformation of cutting tools and workpieces. Cutting forces are affected especially by workpiece materials (the harder is the workpiece material, the higher cutting forces take place), tool geometry and applied cutting conditions.

The optimum values of functional parameters of the surface were obtained by the milling insert ADKW 150508 PDR ID8. Regarding the fact that quality of the machined surface is one of the key factors that affect a price of a workpiece, it is necessary to select an appropriate value considering its future functions to which the given product is produced for.

\section{Acknowledgement}

The article was made under support grant project $K E G A 011 \check{Z} U-4 / 2020$ Implementation of online education in the field of bearing technology with an emphasis on the educational process for improving the skills and flexibility of engineering technology students.

\section{References}

[1] VASILKO, K. a kol. (2006). Top trendy v obrábaní III. čast' - Technológia obrábania. Žilina: MEDIA/ST, 2006. 214 p. ISBN: 80-968954-27

[2] SEDLÁK, J., TROPP, P., CHLADIL, J., KOUŘIL, K. POLZER, A. OSIČKA, K. (2016). Analysis of Selected Aspects of Turned Bearing Rings Regarding Required Workpiece Quality. Manufacturing Technology, Vol. 2016, No.3, pp. 612-622.

[3] HUMÁR, A. (2008). Materiály pro rezzné nástroje. MM publishing s.r.o., $235 \mathrm{~s}$.

[4] http://www.ceramtec.cz/ceramic-materials/> [cit. 2013-10-21]
[5] NOVOTNÝ, J., LYSONKOVA, I., NAPRSTKOVA, N., MICHNA, S. (2017). Research of application possibilities of selected mechanically alloyed metal powders, In Manufacturing Technology, vol. 17, no. 5, pp. 811-815

[6] PAGÁČ, M., MALOTOVÁ, Š., SADÍLEK, M., PETRŮ, J., ZLÁMAL, T., KRATOCHVÍL， J. (2016). Influence of effective milling strategies on the residual stress. In. METAL 2016, Conference Proceedings 2016, pp. 819-824

[7] MONKOVA, K., SUN, S., MONKA, P.P., HLOCH, S., BELAN, M. (2020) Durability and tool wear investigation of HSSE-PM milling cutters within long-term tests. In. Engineering Failure Analysis, Vol. 108, Art. Num. 104348

[8] KUCZMASZEWSKI, J., ZAGORSKI, I., GZIUT, O., LEGUTKO, S., KROLCZYK, G.M. (2017). Chip fragmentation in the milling of AZ91HP magnesium alloy. In. Strojniski Vestnik/Journal of Mechanical Engineering. Vol. 63, Issue 11, 2017, pp. 628-642

[9] MAREK, M., NOVÁK, M., ŠRAMHAUSER, K., SVOBODOVÁ, J. (2018) Analysis of the base material and Hard chrome plated layer in an unloaded state. Manufacturing Technology, 18(4), pp. 616-620

[10] ČUBOŇOVÁ, N., KURIC. I. (2014) Data structures implementation of the protocol STEP-NC at CNC machines programming. In: Communications, vol. 16, no. 3A, pp. 176-183.

[11] BOTKO, F., HATALA, M., KORMOŠ, M., UNGUREANU, N., \& ŠOLTÉS, P. (2015). Using Edgecam for creating CNC programs in education process. In 2015 IEEE 13th International Symposium on Applied Machine Intelligence and Informatics (SAMI) (pp. 255-259). IEEE.

[12] KALINCOVÁ, D., ŤTAVODOVÁ, M., JAKUBÉCZYOVÁ, D. (2018) Quality evaluation of the coatings and its influence on the wood machining tool wear. Manufacturing Technology, 18(4), pp. 578-584

[13] NOVÁ, I., FRAŇA, K., MACHUTA, J., NOVÁKOVÁ, I. (2019) Theoretical calculations of the foaming properties of powder agents for the production of Aluminium foams. Manufacturing Technology, 19(1), pp. 118-122

[14] ČEP, R. PETRU, J., ZLÁMAL, T., VALÍČEK, J., HARNIČÁROVÁ, M., JANÁSEK, A., ČEPOVÁ, L. (2013) Influence of Feed Speed on Machined Surface Quality, In. METAL 2013, pp.1033-1038. 